\title{
Claim Assessment Models in Crop Insurance
}

\section{Alina Regep, Flavia Barna, Horatiu Regep}

To Link this Article: http://dx.doi.org/10.6007/IJARAFMS/v11-i3/10698 DOI:10.6007/IJARAFMS /v11-i3/10698

Received: 16 June 2021, Revised: 18 July 2021, Accepted: 30 July 2021

Published Online: 19 August 2021

In-Text Citation: (Regep et al., 2021)

To Cite this Article: Regep, A., Barna, F., \& Regep, H. (2021). Claim Assessment Models in Crop Insurance. International Journal of Academic Research in Accounting Finance and Management Sciences, 11(3), 327337.

\section{Copyright: @ 2021 The Author(s)}

Published by Human Resource Management Academic Research Society (www.hrmars.com)

This article is published under the Creative Commons Attribution (CC BY 4.0) license. Anyone may reproduce, distribute, translate and create derivative works of this article (for both commercial and non-commercial purposes), subject to full attribution to the original publication and authors. The full terms of this license may be seen at: http://creativecommons.org/licences/by/4.0/legalcode

\section{Vol. 11, No. 3, 2021, Pg. 327 - 337}




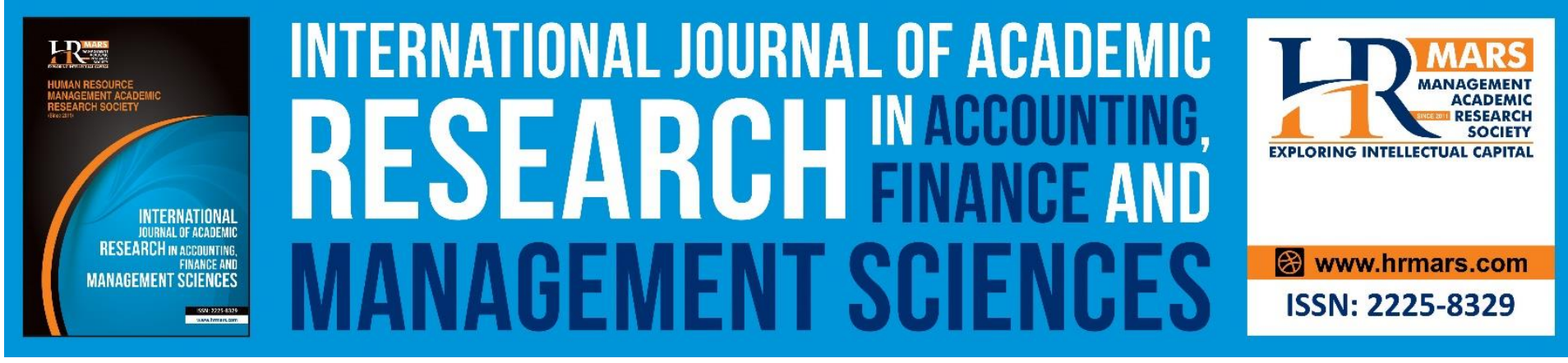

\title{
Claim Assessment Models in Crop Insurance
}

\author{
Alina Regep ${ }^{1}$, Flavia Barna ${ }^{2}$, Horatiu Regep ${ }^{3}$ \\ ${ }^{1}$ Alumni Master of Finance and Banking at Faculty of Economics and Business \\ Administration, West University from Timisoara, ${ }^{2,3}$ Faculty of Economics and Business \\ Administration, West University from Timisoara \\ Email: alina.regep@yahoo.com¹, flavia.barna@e-uvt.ro², horatiu.regep@yahoo.com³
}

\begin{abstract}
Agricultural insurance is considered one of the engines of the development of the agricultural industry. Without a developed of agricultural insurance market, farmers cannot manage their risks to protect their investments, which leads us to say that, in this context, the modernization of the agricultural industry will not succeed. Investments in technology to modernize agriculture in order to increase productivity are very important, and in order to have stability, there must be tools on the insurance market to protect farmers. The larger the insurance market, the more diversified protection instruments exist as options for the farmers.

In order for the insurance market to be able to develop and come to farmers with diversified products, the involvement of the state with different financing measures / schemes is needed. At the international level, depending on each country, the state is involved with different schemes. The more the state is involved, the more developed the insurance market is, which led to an increase in the well-being of the agricultural sector. The impact on the insurance market was not only in diversifying the protection instruments but also in reducing their cost. This has led to the possibility for farmers to transfer to the insurance market several types of risks at sustainable costs.

Starting from the importance of the way in which a claim assessment is performed, in this paper we propose to make a comparative study between a classical method of claim assessment in the case of agricultural crops and a modern method of assessment based on satellite data/images. The comparative analysis aims to highlight the impact of different methods in establishing the final value that the farmer is going to collect from the insurer.
\end{abstract}

Keywords: Crop Insurance, Claim Assessment, Ndvi, Climate Risk, Loss Ratio

\section{Introduction}

Agriculture insurance market is very important in the country economic cycle as it is considered the engine of the development of the agriculture industry. We selected to analyze this sector as the agriculture sector from our point of view is one of the most important sector in the economic structure of a country. All over the world and agriculture sector exist and is directly influenced by external factors as climate change and digitalization. Due to the development of digitalization we believe that this can help farmers to better mitigate their risk. The advantage 
MANAGEMENT SCIENCES

Vol. 11, No. 3, 2021, E-ISSN: 2225-8329 @ 2021 HRMARS

of digitalization is present not only to the farmers but also to the insurers, the entities were farmers transfer mainly the meteorological risks.

At this moment the digital innovation affects all industries and if we apply the benefits from digitalization to the agriculture industry we can create better risk management solutions for the farmers to better protect their yields, assets and revenue. Starting from these aspects in this paper we proposed to start the analyze from the way an insurer assess a claim in case of meteorological risk.

We strongly believe that if the farmers benefits of better risk management tools than they will have better yields which leads to a better country crop production which automatically will increase the economic power of that country. In the end the risk of starvation will decrease, which at this moment at global level is a factor that is taken into account.

We expect that through this paper to better understand which are the advantages for all the parties: insurers and farmers. In general, by using digitalization the risk of human error is reduces and the time to assess a claim is reduce. From the insurer point of view they can better assess a claim and reduce their cost of that assessment. From the farmer point of view they can receive more fast the indemnity in case of a claim and of course they can access new insurance products in order to transfer new risks to the insurance market.

\section{Literature Review}

The agricultural insurance market began to develop in Europe more than 200 years ago, in the form of providing private protection against named peril events such as crop-hail. In the last 50 years, however, there have been an accelerated development of insurance products, which have come to the aid of agricultural producers. This rapid development occurred as a result of the support provided by the government, in terms of subsidized premiums, loss adjustment expenses and the public provision of reinsurance services.

By 2007, premium subsidies among high income countries totaled almost $\$ 12$ billion (Mahul \& Stutley, 2010). Since 2007 and until now, subsidy programs have grown rapidly, with subsidized insurance premiums reaching increases of over $100 \%$. While the United States crop insurance program is the world's largest in premium volume, similar programs are found also in Italy, Spain and Canada, France, Austria (Glauber, 2012). New insurance programs started to be discussed and developed in emerging countries from Eastern Europe. As example in Romania the discussions started in 2020 and in 2021 the Government decided to create a working group to prepare an agriculture state scheme.

Government involvement in multiple peril crop insurance began in the late-1930s in the United States. Federal crop insurance was first authorized in Title $V$ of the Agricultural Adjustment Act of 1938 (Benedict, 1953; Kramer, 1983). The pilot program initially provided coverage only for wheat crops. In 1939, about 165,000 wheat policies were issued on approximately 7 million acres in 31 states (Rowe \& Smith, 1940). Canada implemented the first multi-risk agricultural insurance legislation in 1959 (Sigurdson \& Sin, 1994). After World War II, several multi-risk agricultural insurance programs were gradually implemented in Europe (Mahul \& Stutley, 2010; OECD, 2011), with subsidized programs implemented in Austria in 1955, Italy in 1970, Spain in 1980 and France in 2005. Taking into account that in 2021 Romanian government created the working group in order to implement a state scheme we expect that also Romania will have scheme starting 2022/2023.

All these actions of the states have led to the increase of the agricultural insurance markets, which implicitly has led to the existence of several types of agricultural insurance products, aspect that helps the farmers in identifying better solutions for managing the climate risk. 
MANAGEMENT SCIENCES

Vol. 11, No. 3, 2021, E-ISSN: 2225-8329 @ 2021 HRMARS

However, it is not only important how we transfer climate risk to the insurance market, but it is also very important to analyze how the claim is assessed. Depending on how the claim is assessed, the farmer may recover different amounts of indemnities from the insurers. Thus, there are several methods that we want to analyze in this paper. The first method we analyze is the one considered classic because it is done directly in the field by specialized agronomic engineers. The second method we will consider is the one based on satellite data.

In the last decade, numerous studies show the importance of satellite data analysis. (Kerr \& Ostrovsky, 2003; Turner et al., 2003) and especially the vegetation index with nominal difference (NDVI)( Pettorelli et al., 2005b). NDVI was first reported by Rouse paper (Rouse et al., 1974) and is calculated as:

$$
N D V I=\frac{N I R-R e d}{N I R+R e d}
$$

NIR and Red - are the amount of infrared and bright red light reflected on an area measured by satellite.

The subsequent study mainly referred to the use of the transformed vegetation index (TVI) and does not contain information on the use of NIR / Red ratios such as Birth and McVey (1968), Jordan (1969), and Pearson and Miller (1972). Subsequently, Tucker (1977), Tucker (1979), and Deering (1978) employed the NDVI to estimate herbaceous biomass and Tucker et al. (1981) showed how frequently NDVI measurements were strongly correlated with the total accumulation of herbaceous dry matter in the observation period. Green leaves absorb solar radiation in regions with active photosynthetic radiation that produce the energy needed to power photosynthesis (Jensen, 2007). More specifically, green leaves have a high degree of absorption of solar radiation in the blue and red spectral regions, but not as much in the green spectral regions. Near the red spectral regions, the green leaves are highly reflective and no absorption occurs (Knipling,1970; Jensen, 2007). Green leaves have high visible light absorption together with high near-infrared reflectance, resulting in positive NDVI values. Empty soil, clouds, snow, concrete, have NDVI values close to zero while water has negative NDVI values (Neigh et al., 2008).

The NDVI index offers the possibility to monitor the photosynthesis of vegetation in time and allows temporal and spatial comparisons (Myneni et al., 1997). It can be used to map, assess or predict the occurrence and impact of disturbances such as drought, fire, flood and frost (Pettorelli et al., 2005b), as well as helping to map and predict the extent of land degradation (Prince et al., 2009).

As mentioned above, we will perform an analysis by comparative method of the two ways of assessing a claim in the case of crop insurance. The analysis takes into account an event that happened to a farmer in Romania in 2020. The analyzed risks that we take into account are storm and torrential rains in the case of corn fields. Following the finding, it was observed that the plants were broken and fell to the ground, respectively the cobs were detached from the stem and fell to the ground. A confirmation of the event was also obtained from the Regional Meteorological Center in the region where the crops are located. The meteorological diagnosis on the day of the event was claiming that in that area there were phenomena of hail, rain showers and electric discharges.

\section{Classical Claim Assessment}

Following the occurrence of the insured event, the always the farmer must notify the insurance company within 48 hours. In this sense, the damage notification form is filled in. The damage inspector has the obligation to go to the scene, in order to evaluate the damages 


\section{MANAGEMENT SCIENCES}

Vol. 11 , No. 3, 2021, E-ISSN: 2225-8329 @ 2021 HRMARS

produced and to draw up a report of finding. Based on the insurance policy which is paid and valid and on the statement the loss adjuster draws up a notice of approval from which the famer must identify the level of the indemnity. Separately from this procedure the loss adjuster requests a series of documents. Thus, in the case of a storm, it is required:

- Weather station address

- Proof of the right to use the land (either the address from State or a statement from the mayor's office)

- Proof of the insured price in the policy (either it is automatically accepted if the price is in the market average, or invoices or contracts are provided).

In our analysis, we will consider only one plot to make it easier to exemplify the comparison with modern analysis. Therefore, going through the above steps, it is found that the storm affected plot 699 (58.4 hectares), which includes soils 2 (36.2 hectares), 4 (18 hectares) and 6 (4.1 hectares).

Based on the information provided by the insured, the loss adjuster travels to the field together with the insured to analyze the degree of damage from the insured risks. The method applied is one of a quantitative nature. For the entire plot 4 samples are established and the degree of damage from insured risks is calculated. The method for each sample involves the following steps:

- Select a row with a length of $14.3 \mathrm{~m}$;

- The number of plants on the selected length is determined;

- Count the cobs dropped on the floor and weigh them to determine the weight;

- Count the cobs on the plants and weigh them to determine the kilograms;

- It is determined total $\mathrm{kg}$ of cobs by adding the $\mathrm{kg}$ on the ground with those on the plants. Thus, the production obtainable in the field is identified;

- Based on the kilograms obtained, it is extrapolated to the hectare level. The calculation is made as follows: the kilograms obtained are multiplied by 839.9 and we will have the production per hectare;

- The production from the ground compared to the obtainable production will determine the degree of damage on each sample;

- The average of the samples will determine the degree of damage on the considered plot 
MANAGEMENT SCIENCES

Vol. 11, No. 3, 2021, E-ISSN: 2225-8329 @ 2021 HRMARS

In our case the results on each sample are presented in the table below.

Table 1: Analysis of the corn plot

\begin{tabular}{|l|l|l|l|l|}
\hline & Sample 1 & Sample 2 & Sample 3 & Sample 4 \\
\hline Number of Plants & 57 & 54 & 54 & 51 \\
\hline $\begin{array}{l}\text { Corn cobs on the floor } \\
\text { Number }\end{array}$ & 40 & 24 & 30 & \\
$\begin{array}{l}\text { Kg } \\
\text { Kg/hectare }\end{array}$ & 5.24 & 3.18 & 4 & 14 \\
\hline $\begin{array}{l}\text { Corn cobs on plants } \\
\text { Number }\end{array}$ & 4401 & 2671 & 3360 & 2.15 \\
Kg & 19 & 23 & 21 & 1806 \\
Kg/hectare & 2.25 & 2.45 & 2.49 & 41 \\
\hline Total production obtainable/hectare & 6291 & 4729 & 5451 & 6435 \\
\hline Insured production (kg)/hectare & 7000 & 7000 & 7000 & 7000 \\
\hline Sum insured (lei)/Hecate & 3850 & 3850 & 3850 & 3850 \\
\hline Uninsured Risk & $10.13 \%$ & $32.45 \%$ & $22.13 \%$ & $10.85 \%$ \\
\hline Insured risk & $69.96 \%$ & $56.48 \%$ & $61.64 \%$ & $28.28 \%$ \\
\hline
\end{tabular}

Source: made by the author based on the information obtained during the evaluation 2020

It can be seen that a considerable proportion of the crop is affected by uninsured risks. The uninsured risk in our case is drought. Regarding the insured risks, there is a very high degree of damage. The storm had a major impact on the corn crop. The average degree of damage on the plot of 699 of 58.4 hectares, determined by the average of the 4 samples, is $54.09 \%$. If the farmer agrees with this method of calculating the degree of damage, he will fill in and sign the finding process without objections. If the farmer does not agree with this method, then according to the contract conditions he will wait until harvest, when the degree of damage would have been determined on the basis of weighing notices. This method involves, in the first phase, the identification of an unaffected plot, in order to determine the obtainable production in the field, and in the second phase, at harvest, all the scales of the affected plot 699 are collected and the total harvested production is determined. The yield harvested on the affected will be compared with an unaffected area and the degree of damage is determined. In the below table we calculate the indemnity that will be paid to the farmer:

Table2: Classical loss adjustment method

\begin{tabular}{|l|l|}
\hline & Classical loss adjustment \\
\hline Sum insured / hectare (lei) & 3850 \\
\hline Plot 699 (hectare) & 58.4 \\
\hline Total sum insured plot 699 (lei) & 224,840 \\
\hline Claim Ratio plot 699 (\%) & $37,1 \%$ \\
\hline Value of the claim plot 699 (lei) & 83.415 \\
\hline Affected area from the Plot 699 (hectare) & 58.4 \\
\hline Deductible (\%) & $10 \%$ \\
\hline Value of deductible (lei) & 22,484 \\
\hline Value of the indemnity (lei) & 99,132 \\
\hline
\end{tabular}

Source: Created by the author based on the information from the contract and the field 
MANAGEMENT SCIENCES

Vol. 11, No. 3, 2021, E-ISSN: 2225-8329 @ 2021 HRMARS

As it can be seen the by applying the claim ratio to the plot, we identify the value of the damage and afterwards we deducted the deductible which is applied to the affected are in order to determine indemnity to be paid to the farmer by the insurer. In order for the insurer to pay this amount, the client must confirm it by completing the final claim document need it for the payment. Based on this document, the insurer is obliged to pay the amount of the farmer's compensation within 20 days.

\section{Modern Damage Analysis}

For this method we use the development of technology as a principal factor to quantify the loss ratio. Satellite images due to the increasing and diversifying number of sensors, the synoptic vision of the territory and the multitude of biophysical and geomorphological data they represent, are considered as a very important and useful tool in the management of extreme phenomena (drought, rainfalls, floods, forest fires, etc.). Remote sensing data provides spectral information that has proven effective in many disaster management applications. In general, field monitoring networks are insufficient due to the low density of observation points; satellite platforms provide fairly wide spatial coverage without access restrictions. Biophysical, biological or structural parameters of vegetation can be extracted from remote sensing data: leaf surface index-LAl, biomass, daily fraction of active photosynthetic radiation absorbed by vegetation cover-APAR, vegetation index normalized difference-NDVI, water index normalized difference NDWI, drought index normalized difference NDDI etc.

The Normalized Difference Vegetation Index (NDVI) as mentioned before is a non-linear transformation of the visible bands (RED) and near infrared bands (NIR). NDVI is a "unit of measurement" of vegetation development and density and is associated with biophysical parameters such as: biomass (tons / ha), leaf area index (LAI), used very often in crop growth models, the percentage of land cover with vegetation, the photosynthetic activity of vegetation. In general, NDVI values are between -1.0 and 1.0, negative values indicating clouds or water, and positive values close to 0 indicating uncovered soil, high positive NDVI values indicate sparse vegetation (0.1-0.5) to dense vegetation (>0.6). Indirectly, NDVI is used to estimate the effects of rainfall over a period of time, to estimate the vegetation status of different crops and the quality of the environment as a habitat for various animals, pests and diseases.

The modern method proposed to determine the degree of damage involves the use of the NDVI index. This involves identifying a correlation of this index with the natural phenomena (storm) that occurred in 2020. Following the analysis of the data, it was found that there is a correlation between the reflectance level (NDVI) and the level of damage in case of a storm that affected a corn crop:

- storms primarily affect yields by defoliating maize and reducing the number of stems, so that the spectral responses of maize are different depending on the intensity of the storm;

- therefore, the analysis of these spectral curves indicates that there is a positive correlation between the reflection values and the levels of damage in the visible spectrum;

- it was found that the percentage of defoliation using this method is more accurate than a field survey "7-10 days after the storm "

The method of calculation by image analysis differs from the classical method of establishing damage by finding in the field. Thus, by the method based on the image analysis we determine the stage of the plant before and after the storm, having the possibility to estimate the affected area and the structural changes of the plant. 
MANAGEMENT SCIENCES

Vol. 11, No. 3, 2021, E-ISSN: 2225-8329 @ 2021 HRMARS

Below we present the spectral images made with the help of satellites. The imagery can be found on plot 699 on floors 2, 4 and 6 . Note the comparison of images before and after the storm:

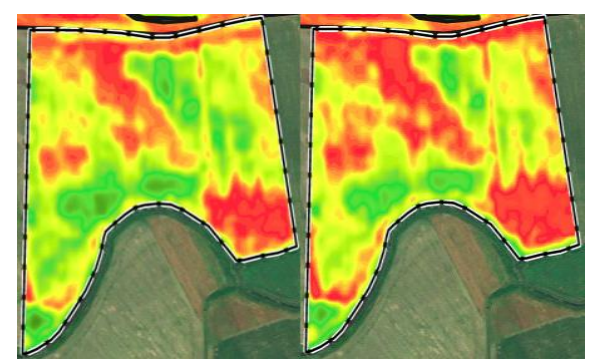

Sole 2

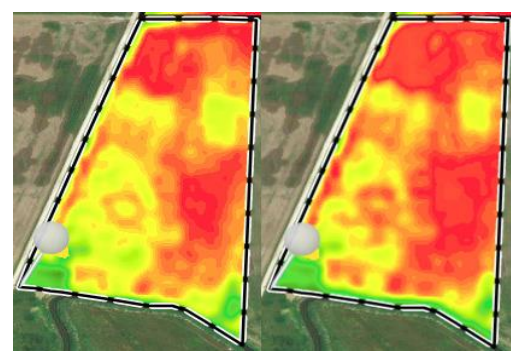

Sole 4

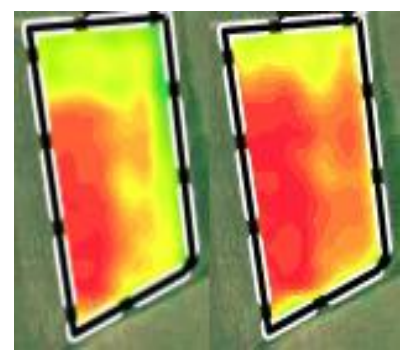

Sole 6

Figure 1 Analysis of images obtained based on the NDVI index

Source: made by the author based on information obtained from the satellite

It is important to understand that green areas are areas that are not affected by storms or any weather risk, and red areas are those that are affected by natural phenomena. This comparative analysis before and after the storm shows us a very interesting aspect. The prestorm culture has many affected areas, which means that it has already been affected by other risks. In this case, we are talking about the risk of drought. However, we are only interested in the damage caused by the storm because this is the risk insured by the farmer. The result based on the analysis is that out of the total of 58.4 hectares, only 37 are affected by different degrees of damage. Referring to the entire surface, the degree of damage from the determined storm risk is $37.1 \%$. The high impact in determining this degree of damage has the sole number 2 because is the largest in area, but it can also be seen that in the middle of the sole no. 2 there are quite many green areas. This aspect influenced the determination of the loss ratio to only $37.1 \%$.

Applying these results to the information we have in the insurance policy, we will have the following result:

Table3: Modern loss adjustment method

\begin{tabular}{|l|l|}
\hline & Modern loss adjustment \\
\hline Sum insured / hectare (lei) & 3850 \\
\hline Plot 699 (hectare) & 58.4 \\
\hline Total sum insured plot 699 (lei) & 224,840 \\
\hline Claim Ratio plot 699 (\%) & $37,1 \%$ \\
\hline Value of the claim plot 699 (lei) & 83.415 \\
\hline Affected area from the Plot 699 (hectare) & 37 \\
\hline Deductible (\%) & $10 \%$ \\
\hline Value of deductible (lei) & 14,245 \\
\hline Value of the indemnity (lei) & 69,170 \\
\hline
\end{tabular}

Source: Created by the author based on the information from the contract and the NDVI index

As it can be seen the by applying the claim ratio to the plot, we identify the value of the damage and afterwards we deducted the deductible which is applied to the affected area in order to determine indemnity to be paid to the farmer by the insurer. It is very important to 
MANAGEMENT SCIENCES

Vol. 11, No. 3, 2021, E-ISSN: 2225-8329 @ 2021 HRMARS

see that we have some important differences compared to the classical method. First of all the claim ratio us lower because with the satellite we managed to identify more accurate the regions where the plot was not affected. Also because of the same reason we identify that not the entire plot 699 was affected, only 27 hectares from 58,4 hectare. Because of more accurate information we managed to indenting more correctly the indemnity to paid to the farmer

\section{Conclusion}

In this paper we focused on how to quantify the damage due to the occurrence of the risk of storm from 2020 affecting a plot of 58.4 hectares. The analysis is performed by two methods, the classic one by sending a loss adjuster in the field, and the second method based on satellite images. It should be mentioned that currently, in Romania, only the method with the loss adjuster is used. The second method represents an innovation in the field both in Romania and internationally.

Thus, by the classical method it was observed that the surface was affected not only due to the insured risks, the storm, but also due to the uninsured risks, the drought. After the sample assessment, a degree of damage of $54.09 \%$ is determined over the entire damaged area.

The satellite image method involves analyzing the affected area based on the NDVI index. If in the case of the classical method samples are used and an average is made, in the case of the modern method the vegetation stage of the plant is identified before and after the storm, and the degree of damage is determined by the registered changes. Based on these methods, a degree of damage of only $37.1 \%$ is identified.

It can be seen that there is a major difference in results by using the two methods. The main reason is that the classical method has the limitation of the human factor, which makes an average of some samples. Given that the plot has 58.4 hectares, it is impossible for a man to physically cover the entire plot to calculate the degree of damage. If we analyze the result from the point of view of a farmer, we are tempted to say that the classical method is better, but this method is always subject to uncertainty due to the human factor. In our opinion, the satellite method is the most correct because it does not take into account the human error that can occur in the selection of samples. Moreover, this method does not involve the additional presentation of documents as in the classical approach, and the calculation of the degree of damage can be done in 1-2 days from the occurrence of the damage.

\section{Reference}

Benedict, M. R. (1953). Farm Policies of the United States, 1790-1950: A Study of Their Origins and Development, New York: The Twentieth Century Fund. DOI: https://doi.org/10.1017/S0003055400274261

Birth, G. S., McVey, G. R. (1968). Measuring color of growing turf with a reflectance spectrophotometer. American Society of Agronomy, 60, 640-645. DOI:10.2134/AGRONJ1968.00021962006000060016X

Deering, D.W. (1978). Rangeland reflectance characteristics measured by aircraft and spacecraft sensors [Doctoral Dissertation, Texas A \& M University]. College Station. https://hdl.handle.net/1969.1/DISSERTATIONS-253780

Glauber, J. W. (2012). The Growth of the Federal Crop Insurance Program, 1990-2011. American Journal of Agricultural Economics, 95(2), 482-88. DOI:10.1093/ajae/aas091 
MANAGEMENT SCIENCES

Vol. 11, No. 3, 2021, E-ISSN: 2225-8329 ๔ 2021 HRMARS

Jensen, J.R. (2007). Remote sensing of the environment: an earth resource perspective, 2 nd Edition. Prentice Hall. Upper Saddle River. https://pdfs.vip/downloads/remotesensing-of-the-environment-an-earth-resource-perspective

Jordan, C. F. (1969). Derivation of leaf-area index from quality of light on forest floor. Ecology, 50 (4), 663-666. https://doi.org/10.2307/1936256

Kerr, J. T., \& Ostrovsky, M. (2003). From space to species: ecological applications for remote sensing. Trends in Ecology \& Evolution, 18 (6), 299-305. DOI:10.1016/S01695347(03)00071-5

Knipling, E. B. (1970). Physical and physiological basis for the reflectance of visible and near infrared radiation from vegetation. Remote Sensing Environment, 1(3), 155-159. https://doi.org/10.1016/S0034-4257(70)80021-9

Kramer, R. A. (1983). Federal Crop Insurance 1928-1982. Agricultural History, 57(1), 181-200. https://www.jstor.org/stable/3743155

Mahul, O., \& Stutley, C. (2010). Government Support to Agricultural Insurance Challenges and Opportunities for Developing Countries, World Bank. DOI: 10.1596/978-0-8213-82172

Myneni, R. B., Keeling, C. D., Tucker, C. J., Asrar, G., \& Nemani, R. R. (1997). Increased plant growth in the northern high latitudes from 1981 to 1991. Nature, 386, 698-702. https://doi.org/10.1038/386698a0

Neigh, C. S. R., Tucker, C. J., \& Townshend, J. R.G. (2008). North American vegetation dynamics observed with multi-resolution satellite data. Remote Sensing Environment, 112(4), 1749-1772. https://doi.org/10.1016/j.rse.2007.08.018

Organisation for Economic Co-operation and Development. (2011). Managing Risk in Agriculture: Policy Assessment and Design. Paris. https://ebooknew.com/gets/book.php?id=c0U1INBqXc8C\&item=managing-risk-in-agriculturepolicy-assessment-and-design\&data=printisdeadbook.com

Pearson, R.L., \& Miller, L.D. (1972 October 2-6). Remote Mapping of Standing Crop Biomass for Estimation of the Productivity of the Shortgrass Prairie. Proceeding of the Eight International Symposium on Remote Sensing Environment, Ann Arbor, MI, USA, 2, 1357-1381.

https://www.bibleandbookcenter.com/gets/book.php?id=XnoBzQEACAAJ\&item=pro ceedings-of-the-eighth-international-symposium-on-remote-sensing-ofenvironment-2-6-october-1972

Pettorelli, N., Vik, J. O., Mysterud, A., Gaillard, J. M., Tucker, C. J., \& Stenseth, N. C. (2005b). Using the satellite-derived Normalized Difference Vegetation Index (NDVI) to assess ecological effects of environmental change. Trends in Ecology \& Evolution, 20 (9), 503510. DOI:https://doi.org/10.1016/j.tree.2005.05.011

Prince, S. D., Becker-Reshef, I., \& Rishmawi, K. (2009). Detection and mapping of long-term land degradation using local net production scaling: application to Zimbabwe. Remote Sensing Environment ,113 (5), 1046-1057. https://doi.org/10.1016/j.rse.2009.01.016

Rouse, J. W., Haas, R. H., Schell, J. A., Deering, D. W. (1974). Monitoring vegetation systems in the Great Plains with ERTS. Third Earth Resources Technology Satellite-1 Symposium, 1(A), 309-317. https://core.ac.uk/reader/42893139

Rowe, W. H., \& Smith, L. K. (1940). Crop Insurance. Yearbook of Agriculture, 1940: Farmers in a Changing World. Washington, DC: U.S. Department of Agriculture. https://www.worldcat.org/title/farmers-in-a-changing-world/oclc/784830598 
Sigurdson, D., \& Sin, R. (1994). An Aggregate Analysis of Canadian Crop Insurance Policy. In Hueth D. L., Furtan W. H. eds. Economics of Agricultural Crop Insurance: Theory and Evidence. Natural Resources Management and Policy. Springer, Dordrecht https://doi.org/10.1007/978-94-011-1386-1_3

Tucker, C. J. (1977). Spectral estimation of grass canopy variables. Remote Sensing Environment, 6 (1), 11-26. https://doi.org/10.1016/0034-4257(77)90016-5

Tucker, C. J. (1979). Red and photographic infrared linear combinations for monitoring vegetation. Remote Sensing Environment, 8 (2), 127-150. https://doi.org/10.1016/0034-4257(79)90013-0

Turner, W., Spector, S., Gardiner, N., Fladeland, M., Sterling, E., \& Steininger, M. (2003). Remote sensing for biodiversity science and conservation. Trends in Ecology \& Evolution, 18(6), 306-314. https://doi.org/10.1016/S0169-5347(03)00070-3

Tucker, C. J., Holben, B. N., Elgin, J.H., \& McMurtrey, J. E. (1981). Remote sensing of total drymatter accumulation in winter wheat. Remote Sensing Environment, 11, 171-189. https://doi.org/10.1016/0034-4257(81)90018-3 